\title{
TITLE:
}

\section{Lattice dynamics and thermodynamical properties of silicon nitride polymorphs}

\section{$\operatorname{AUTHOR}(S)$ :}

Kuwabara, Akihide; Matsunaga, Katsuyuki; Tanaka, Isao

\section{CITATION:}

Kuwabara, Akihide ...[et al]. Lattice dynamics and thermodynamical properties of silicon nitride polymorphs. PHYSICAL REVIEW B 2008, 78(6): 064104.

\section{ISSUE DATE:}

2008-08

URL:

http://hdl.handle.net/2433/84633

\section{RIGHT:}

(C) 2008 The American Physical Society 


\title{
Lattice dynamics and thermodynamical properties of silicon nitride polymorphs
}

\author{
Akihide Kuwabara, ${ }^{1}$ Katsuyuki Matsunaga, ${ }^{2}$ and Isao Tanaka ${ }^{2}$ \\ ${ }^{1}$ Nanostructure Research Laboratory, Japan Fine Ceramics Center, 2-4-1 Mutsuno, Atsuta-ku, Nagoya 456-8587, Japan \\ ${ }^{2}$ Department of Materials Science and Engineering, Kyoto University, Yoshida, Sakyo, Kyoto 606-8501, Japan
}

(Received 24 February 2008; published 6 August 2008)

\begin{abstract}
The lattice dynamics of three polymorphs of $\mathrm{Si}_{3} \mathrm{~N}_{4}, \alpha, \beta$, and $\gamma$ phases, has been calculated by the real space force constant method combined with first-principles calculations. The thermodynamical properties of the three phases are evaluated from the vibrational density of states. The effect of thermal volume expansion is included by quasiharmonic approximation. The volume expansivity, bulk modulus, specific heat, and Helmholtz free energy of the three phases are computed as a function of temperature. All three phases are found to be dynamically stable. $\beta$ - $\mathrm{Si}_{3} \mathrm{~N}_{4}$ shows lower Helmholtz free energy than $\alpha-\mathrm{Si}_{3} \mathrm{~N}_{4}$ in the temperature range from 0 to $2000 \mathrm{~K}$. In other words, $\alpha-\mathrm{Si}_{3} \mathrm{~N}_{4}$ is not a low-temperature phase but a metastable phase under the ordinary pressure. The presence of planer $\mathrm{N}-\mathrm{Si}_{3}$ units and their strong Si-N bonds in two hexagonal polymorphs, $\alpha$ - and $\beta$ - $\mathrm{Si}_{3} \mathrm{~N}_{4}$, is the origin of the high-frequency phonon band at above $25 \mathrm{THz}$, which is absent in $\gamma-\mathrm{Si}_{3} \mathrm{~N}_{4}$. It plays key roles for anisotropic local vibration of $\mathrm{N}$ atoms. The different temperature dependence of specific heat between $\alpha / \beta$ and $\gamma$ phases can also be ascribed to the structure. The transition pressure from $\beta$ to $\gamma$ phase is computed as a function of temperature. It is found to increase with the rise of temperature.
\end{abstract}

DOI: 10.1103/PhysRevB.78.064104

PACS number(s): 63.20.dk, 64.70.kp, 65.40.-b

\section{INTRODUCTION}

Silicon nitride $\left(\mathrm{Si}_{3} \mathrm{~N}_{4}\right)$ is widely used as engineering ceramics and insulators in the semiconductor technology. Among nonoxide ceramics composed of nitrides and carbides, $\mathrm{Si}_{3} \mathrm{~N}_{4}$ based ceramics generally show better strength and fracture toughness up to elevated temperatures. Because of the superior properties, enormous research works have been made on $\mathrm{Si}_{3} \mathrm{~N}_{4}$ from many different viewpoints ranging from engineering to basic science.

$\mathrm{Si}_{3} \mathrm{~N}_{4}$ has three polymorphs, $\alpha, \beta$, and $\gamma$ phases as shown in Fig. 1. The crystal structures of the $\alpha$ and $\beta$ phases are hexagonal. Their structures are closely related to each other. In both of two phases, $\mathrm{Si}$ and $\mathrm{N}$ atoms have tetrahedral (fourfold) and trigonal (threefold) coordinates, respectively. The unit cells of the $\alpha$ and $\beta$ phases are characterized by planar structure parallel to (0001), a basal plane. $\beta-\mathrm{Si}_{3} \mathrm{~N}_{4}$ has a periodic stacking structure such as $\mathrm{ABAB} \ldots$ in the direction of the $c$ axis. In the case of $\alpha-\mathrm{Si}_{3} \mathrm{~N}_{4}$, the periodicity is ABCDABCD.... Therefore, the lattice constant of $\alpha-\mathrm{Si}_{3} \mathrm{~N}_{4}$ in the $c$ axis is approximately two times longer than that of $\beta$-Si ${ }_{3} \mathrm{~N}_{4}$. These periodicities are illustrated in Figs. 1(d) and 1(e). The trigonal pyramidal unit, $\mathrm{N}-\mathrm{Si}_{3}$, with $\mathrm{N}$ atom at $2 a$ and $2 b$ sites in $\alpha-\mathrm{Si}_{3} \mathrm{~N}_{4}$ and that with $\mathrm{N}$ atom at $2 c$ site in $\beta$ - $\mathrm{Si}_{3} \mathrm{~N}_{4}$, lay parallel to the basal plane. The other $\mathrm{N}-\mathrm{Si}_{3}$ units are vertically placed to the basal plane. Both the $\alpha$ and $\beta$ phases can be synthesized under the ordinary pressure by direct nitridation of silicon or decomposition of precursors such as silicon diimide. On the other hand, the $\gamma$ phase is a high-pressure product. It forms a cubic spinel structure. All of $\mathrm{N}$ atoms have tetrahedral coordination. There are two kinds of coordination numbers for $\mathrm{Si}$ atoms, i.e., tetrahedral (fourfold) and octahedral (sixfold) ones as shown in Fig. 1(c).

A number of theoretical studies have been carried out to clarify the electronic structure of $\mathrm{Si}_{3} \mathrm{~N}_{4}$ and to discuss origins of physical/chemical properties since 1980s. ${ }^{1-8}$ Mechanical and dielectric properties have been evaluated through firstprinciples calculations. ${ }^{9-15}$ Phonon frequencies were examined either by semiempirical ways ${ }^{16-18}$ or by first-principles methods. ${ }^{15,19,20}$ Theoretical works of $\mathrm{Si}_{3} \mathrm{~N}_{4}$ have been ex- (a)

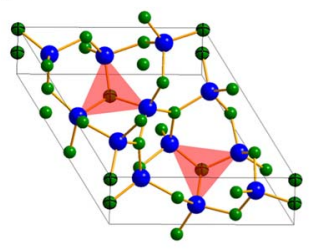

(b)

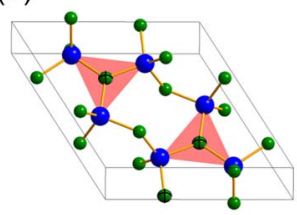

(c)

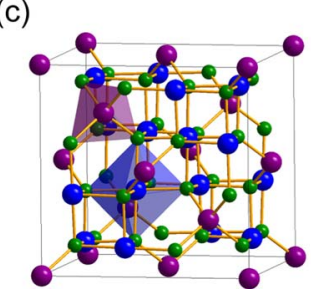

(d)

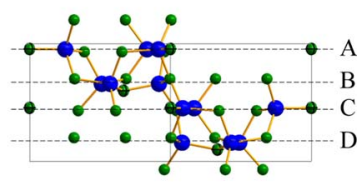

(e)

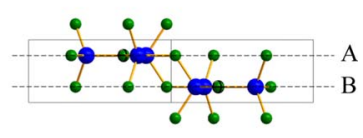

FIG. 1. (Color online) Crystal structure of (a) $\alpha$-, (b) $\beta$ - and (c) $\gamma-\mathrm{Si}_{3} \mathrm{~N}_{4}$ and viewing (d) $\alpha$ - and (e) $\beta$ - $\mathrm{Si}_{3} \mathrm{~N}_{4}$ from [1120] direction. $\mathrm{Si}$ and $\mathrm{N}$ atoms are illustrated by blue and green spheres, respectively. In the panels of $\alpha$ - and $\beta-\mathrm{Si}_{3} \mathrm{~N}_{4}$, trigonal coordination of $\mathrm{N}-\mathrm{Si}_{3}$ parallel to the basal plane is shown by red triangles. In the panel of $\gamma-\mathrm{Si}_{3} \mathrm{~N}_{4}, \mathrm{Si}$ atoms which have tetrahedral coordination are colored by purple. Tetrahedral and octahedral coordination are indicated by purple and blue polyhedra, respectively. Dashed lines in (d) and (e) indicate stacking layers repetition in the direction of $c$ axis of the unit cells. 
tended into various aspects such as a solid solution system of SiAlON, ${ }^{21-28}$ amorphous $\mathrm{Si}_{3} \mathrm{~N}_{4},{ }^{29}$ surface structure, ${ }^{30}$ and intergranular glassy film of $\mathrm{Si}_{3} \mathrm{~N}_{4}$ ceramics. ${ }^{31-36}$

Despite these works, open questions still remain for fundamentals of $\mathrm{Si}_{3} \mathrm{~N}_{4}$. First one is relative phase stability between $\alpha$ - and $\beta-\mathrm{Si}_{3} \mathrm{~N}_{4}$. Both of them can be synthesized and stably existent under ambient conditions. Millimeter-sized single crystals are available for both of them. Submicronsized powders of the $\alpha$ phase are often selected for sintering of high-strength ceramics. $\alpha \rightarrow \beta$ transformation generally occurs when sintered with some oxide additives as liquid phase formers. No back transformation of $\beta \rightarrow \alpha$ occurs except for highly concentrated alloys that prefer the formation of the $\alpha$ phase. These phenomena seem to suggest that $\beta$ is more stable than $\alpha$ at high temperatures. Theoretical analyses for the energetic hierarchy by Grün ${ }^{37}$ using point charge models, first-principles calculations by Ching et al. ${ }^{6}$ and force field simulation by Wendel and Goddard III $^{16}$ have shown that the $\beta$ phase is more stable than the $\alpha$ phase. However, it is still unknown whether the $\alpha$ phase is really a metastable phase at all temperatures and it is formed by a kinetic reason.

Large scattering among experimental data of thermodynamical and physical properties is another remaining problem of $\mathrm{Si}_{3} \mathrm{~N}_{4} \cdot{ }^{38-59}$ Specific heat $\left(C_{P}\right)$ of $\alpha-\mathrm{Si}_{3} \mathrm{~N}_{4}$ can be found in some literature. ${ }^{38,40,42}$ The maximum difference among them reaches $30 \%$. Elastic modulus of $\mathrm{Si}_{3} \mathrm{~N}_{4}$ also shows a large variety. Bulk moduli of $\alpha$ - and $\beta-\mathrm{Si}_{3} \mathrm{~N}_{4}$ experimentally reported thus far shows variation from 228.5 to $281.7 \mathrm{GPa}$, and from 215.4 to $270 \mathrm{GPa}$, respectively. ${ }^{45-58}$ The wide range of the scattering can be mainly ascribed to the lack of single-crystal samples with good quality. When sintered samples are used, properties are strongly dependent on the presence of porosity and impurity used for sintering aid. Under the circumstance, intrinsic properties of $\mathrm{Si}_{3} \mathrm{~N}_{4}$ polymorphs may be better evaluated by first-principles calculations. In order to evaluate the temperature dependence of the properties, we made systematic first-principles phonon calculations of three $\mathrm{Si}_{3} \mathrm{~N}_{4}$ polymorphs in this work.

\section{COMPUTATIONAL METHODOLOGY}

Ground-state structures of three polymorphs were determined by imposing space groups reported by experiments. They are $P 3_{1} c, P 6_{3} / m$, and $F d \overline{3} m$ for the $\alpha, \beta$, and $\gamma$ phases, respectively. As for the $\beta$ phase, calculations were made with $\mathrm{PG}_{3}$ symmetry as well. However, we do not find any evidence to lower the symmetry from $P 6_{3} / m$. This agrees with the conclusion of recent reports by a first-principles calculation $^{8}$ and a synchrotron $x$-ray diffraction study. ${ }^{60}$ In the present study, density functional theory (DFT) calculations $^{61}$ were performed using VASP code. ${ }^{62,63}$ Electron-ion interaction was represented by the projector augmented wave (PAW) method ${ }^{64}$ and the local density approximation (LDA) ${ }^{65}$ was chosen for the exchange and correlation potential. Plane waves up to the energy cutoff of 500 $\mathrm{eV}$ were used as basis functions. Reference configurations for valence electrons were $3 s^{2} 3 p^{2}$ for $\mathrm{Si}$ and $2 s^{2} 2 p^{3}$ for $\mathrm{N}$. Lattice constants and internal positions in primitive cells at various volumes were fully optimized until residual Hellman-Feynmann (HF) forces become smaller than 2.0 $\times 10^{-4} \mathrm{eV} / \AA$. The $\boldsymbol{k}$-point meshes of the Brillouin zone of primitive cells, based on the Monkhorst-Pack scheme, ${ }^{66}$ were $3 \times 3 \times 3$ for $\alpha-\mathrm{Si}_{3} \mathrm{~N}_{4}$ (seven irreducible points), $3 \times 3 \times 7$ for $\beta$-Si ${ }_{3} \mathrm{~N}_{4}$ (12 irreducible points) and $5 \times 5 \times 5$ for $\gamma-\mathrm{Si}_{3} \mathrm{~N}_{4}$ (ten irreducible points) in order to obtain energy convergence of lower than $1 \mathrm{meV}$ per $\mathrm{Si}_{3} \mathrm{~N}_{4}$. Bulk modulus was calculated by the least square fitting of the plot of energy against volume per formula unit to the second order Birch-Murnaghan equation of states. ${ }^{67}$ This means that the derivative of bulk modulus by pressure $\left(B^{\prime}\right)$ was fixed to be four.

Dynamical properties were computed by interatomic force constants in the real space. ${ }^{68,69}$ The whole set of force constants were obtained from HF forces generated by a nonequivalent atomic displacement in a supercell for a given crystal structure. In the present study, dimensions of the supercells were $2 \times 2 \times 2$ and $2 \times 2 \times 4$ of the primitive cells for the $\alpha$ and $\beta$ phases, respectively. Both of the supercells are composed of 224 atoms and only $\Gamma$ point was adopted for the $\boldsymbol{k}$-point sampling. In the case of the $\gamma$ phase, the conventional unit cell including 56 atoms was used. The $\boldsymbol{k}$-point meshes of $2 \times 2 \times 2$ was chosen for this model. It should be noted that all of atomic positions in a supercell were optimized again under these conditions of $\boldsymbol{k}$-point mesh in the supercell. The residual HFs in a supercell after relaxation is smaller than $2.0 \times 10^{-4} \mathrm{eV} / \AA$. A dynamical matrix was constructed from $\mathrm{HF}$ forces acting on all atoms in the supercells with a displaced atom. Total energies and HF forces were calculated using a set of supercells with nonequivalent atomic displacements for each polymorph. The number of supercells for the $\alpha, \beta$, and $\gamma$ phases were 42, 21, and 3, respectively. Phonon frequencies were calculated by solving an eigenvalue problem for the dynamical matrix with satisfying sum rules for lattice constants to hold translational invariance.

In an ionic crystal, atomic displacement induces a dipole. Dipole-dipole interaction remarkably affects interatomic force constants and causes longitudinal optical / transverse optical (LO/TO) splitting at the wavelength vector of $\boldsymbol{k} \approx 0$, namely near $\Gamma$ point. Such dipole interaction can be directly included if the size of a supercell is large enough. ${ }^{70}$ Nonanalytical parameter of Born effective charges ${ }^{71,72}$ also enables one to deal with the LO/TO splitting. However, the present study does not take into account the influence of the dipole on the interatomic force constants, since we are interested in evaluation of thermodynamical quantities derived from the vibrational density of states (VDOS). The inclusion of the LO/TO splitting only slightly changes the VDOS because the dipole-dipole interaction is limited on LO modes with the wavelength vector $\boldsymbol{k} \approx 0$ and leave the frequencies of TO modes unchanged.

\section{RESULTS AND DISCUSSION}

\section{A. Atomic structure at the ground state}

Table I shows optimized lattice parameters and bulk moduli of $\alpha-, \beta$, and $\gamma-\mathrm{Si}_{3} \mathrm{~N}_{4}$ at the ground state. Experimental results in literature are shown together. Compared to 
TABLE I. Crystal structures and bulk moduli of $\mathrm{Si}_{3} \mathrm{~N}_{4}$ obtained by the ground-state calculation and lattice constants from experimental studies.

\begin{tabular}{llllc}
\hline \hline & \multicolumn{4}{c}{$\alpha-\mathrm{Si}_{3} \mathrm{~N}_{4}$} \\
& $a(\AA)$ & $c(\AA)$ & $V\left(\AA^{3}\right)$ & $B(\mathrm{GPa})$ \\
\hline This work & 7.722 & 5.598 & 289.099 & 240 \\
Force field $^{\mathrm{a}}$ & 7.775 & 5.650 & & 270 \\
DFT $^{\mathrm{b}}$ & 7.792 & 5.614 & 295.190 & 257 \\
DFT $^{\mathrm{c}}$ & 7.701 & 5.581 & 286.640 & 257 \\
Experiment $^{\mathrm{d}}$ & 7.75193 & 5.61949 & 292.447 & \\
Experiment $^{\mathrm{e}}$ & 7.7545 & 5.62145 & 292.743 &
\end{tabular}

\begin{tabular}{llllc} 
& \multicolumn{5}{c}{$\beta-\mathrm{Si}_{3} \mathrm{~N}_{4}$} \\
& $a(\AA)$ & $c(\AA)$ & $V\left(\AA^{3}\right)$ & $B(\mathrm{GPa})$ \\
\hline This work & 7.576 & 2.892 & 143.753 & 252 \\
Force field $^{\mathrm{a}}$ & 7.618 & 2.905 & & 283 \\
Hartree-Fock $^{\mathrm{f}}$ & 7.61 & 2.91 & 145.95 & 297 \\
DFT $^{\mathrm{b}}$ & 7.622 & 2.910 & 146.407 & 274 \\
DFT $^{\mathrm{g}}$ & 7.562 & 2.893 & 143.269 & 263 \\
DFT $^{\mathrm{h}}$ & 7.580 & 2.899 & 144.250 & 250 \\
DFT $^{\mathrm{c}}$ & 7.555 & 2.884 & 142.559 & 225 \\
DFT $^{\mathrm{i}}$ & & & & $237.2-241.5$ \\
Experiment $^{\mathrm{j}}$ & 7.6044 & 2.9063 & 145.546 &
\end{tabular}

\begin{tabular}{lccc} 
& \multicolumn{3}{c}{$\gamma-\mathrm{Si}_{3} \mathrm{~N}_{4}$} \\
& $a(\AA)$ & $V\left(\AA^{3}\right)$ & $B(\mathrm{GPa})$ \\
\hline This work & 7.695 & 455.655 & 320 \\
DFT $^{\mathrm{k}}$ & 7.697 & 456.000 & 308 \\
& $(7.793)$ & $(473.276)$ & $(284)$ \\
DFT $^{\mathrm{l}}$ & 7.846 & 482.998 & 335 \\
DFT $^{\mathrm{m}}$ & $7.6640(7.7585)$ & 450.160 & 310.9 \\
& & $(467.018)$ & $(272.5)$ \\
Experiment $^{\mathrm{n}}$ & 7.7351 & 462.805 & \\
\hline
\end{tabular}

\begin{tabular}{|c|c|}
\hline${ }^{\text {aReference } 16}$ & ${ }^{\mathrm{h}}$ Reference 75 \\
\hline${ }^{\mathrm{b}}$ Reference 6 & ${ }^{\mathrm{i}}$ Reference 76 \\
\hline${ }^{\mathrm{c}}$ Reference 32 & ${ }^{\mathrm{j}}$ Reference 60 \\
\hline${ }^{\mathrm{d}}$ Reference 73 & ${ }^{\mathrm{k}}$ Reference 56 \\
\hline${ }^{e}$ Reference 74 & ${ }^{1}$ Reference 28 \\
\hline${ }^{\mathrm{f}}$ Reference 10 & ${ }^{\mathrm{m}}$ Reference 13 \\
\hline${ }^{\mathrm{g}}$ Reference 7 & ${ }^{\mathrm{n}}$ Reference 59 \\
\hline
\end{tabular}

the experiments, our calculation underestimates the lattice constants by $<1 \%$, which is within the general accuracy of DFT using LDA. The lattice volume per $\mathrm{Si}_{3} \mathrm{~N}_{4}$ unit is larger for the $\alpha$ phase than the $\beta$ phase by $0.55 \%$, which agrees to the experimental data, $0.47 \% .{ }^{60,73}$

The bulk modulus of $\beta$ phase is larger than that of $\alpha$ phase. This is consistent with the result of force field calculation ${ }^{16}$ and first-principles calculation. ${ }^{6}$ In contrast, this is opposite to the report by Ogata et ll $^{32}$ in which the averaged theoretical values between bulk moduli obtained from calculations based on LDA and GGA are shown. The $\gamma$ phase
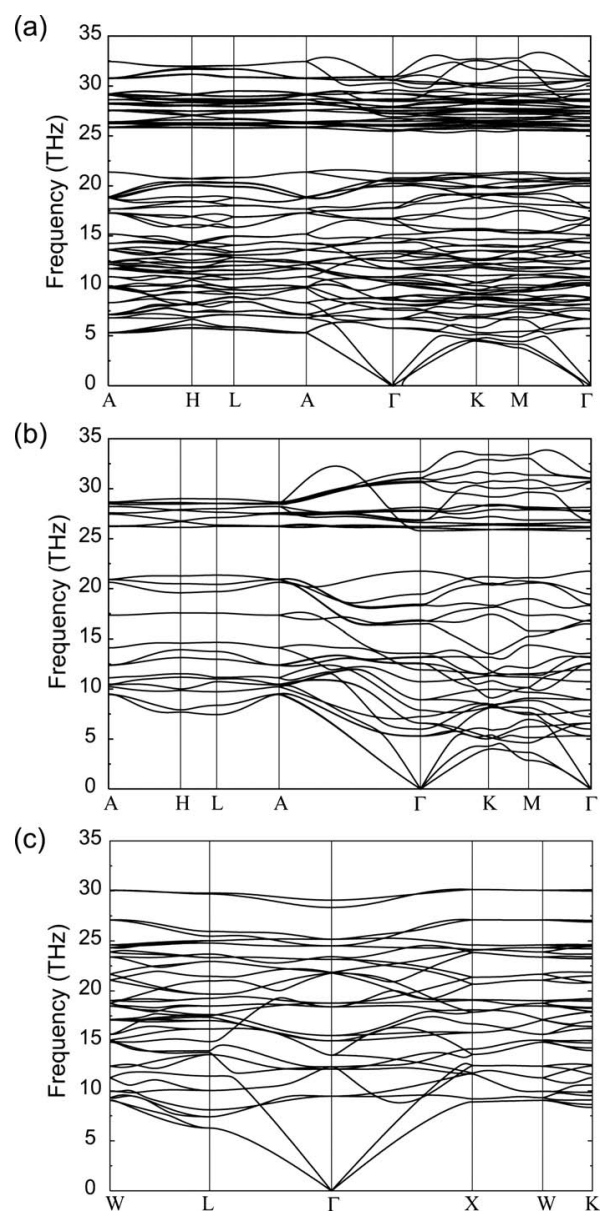

FIG. 2. Phonon dispersion curves for (a) $\alpha$-, (b) $\beta$ - and (c) $\gamma-\mathrm{Si}_{3} \mathrm{~N}_{4}$.

has the highest bulk modulus among three polymorphs, which is consistent to results in literature. ${ }^{13,28,56}$

\section{B. Phonon spectra of three phases}

Figure 2 shows phonon dispersion curves of $\alpha-\beta$-, and $\gamma-\mathrm{Si}_{3} \mathrm{~N}_{4}$. All phonon branches in $\beta$ - and $\gamma-\mathrm{Si}_{3} \mathrm{~N}_{4}$ have real frequency. In $\alpha-\mathrm{Si}_{3} \mathrm{~N}_{4}$, imaginary frequencies of $0.4 i$ and $0.07 i \mathrm{THz}$ are found in a transverse acoustic (TA) mode in the direction of the $\Gamma-K$ and the $\Gamma-A$ line, respectively. It should be noted that $\alpha-\mathrm{Si}_{3} \mathrm{~N}_{4}$ has no imaginary frequency at the exact $\Gamma$ point. These imaginary frequencies are likely an error in a phonon calculation based on the force constant in the supercell model. Insufficient supercell size, tiny residual force, or accuracy of force calculation may be the source of errors. ${ }^{68}$ However, it was unable to conduct calculations with better accuracy for $\alpha-\mathrm{Si}_{3} \mathrm{~N}_{4}$ at the present moment. Since the magnitude of the imaginary frequencies are quite small and it is not located at the zone-center and high-symmetry point, we judge that $\alpha-, \beta$-, and $\gamma-\mathrm{Si}_{3} \mathrm{~N}_{4}$ are stable phases from the viewpoint of lattice dynamics.

Total and partial VDOS of three phases are shown in Fig. 3. Calculated total VDOS, $g_{\text {total }}(\omega)$, was normalized to satisfy the following condition, 

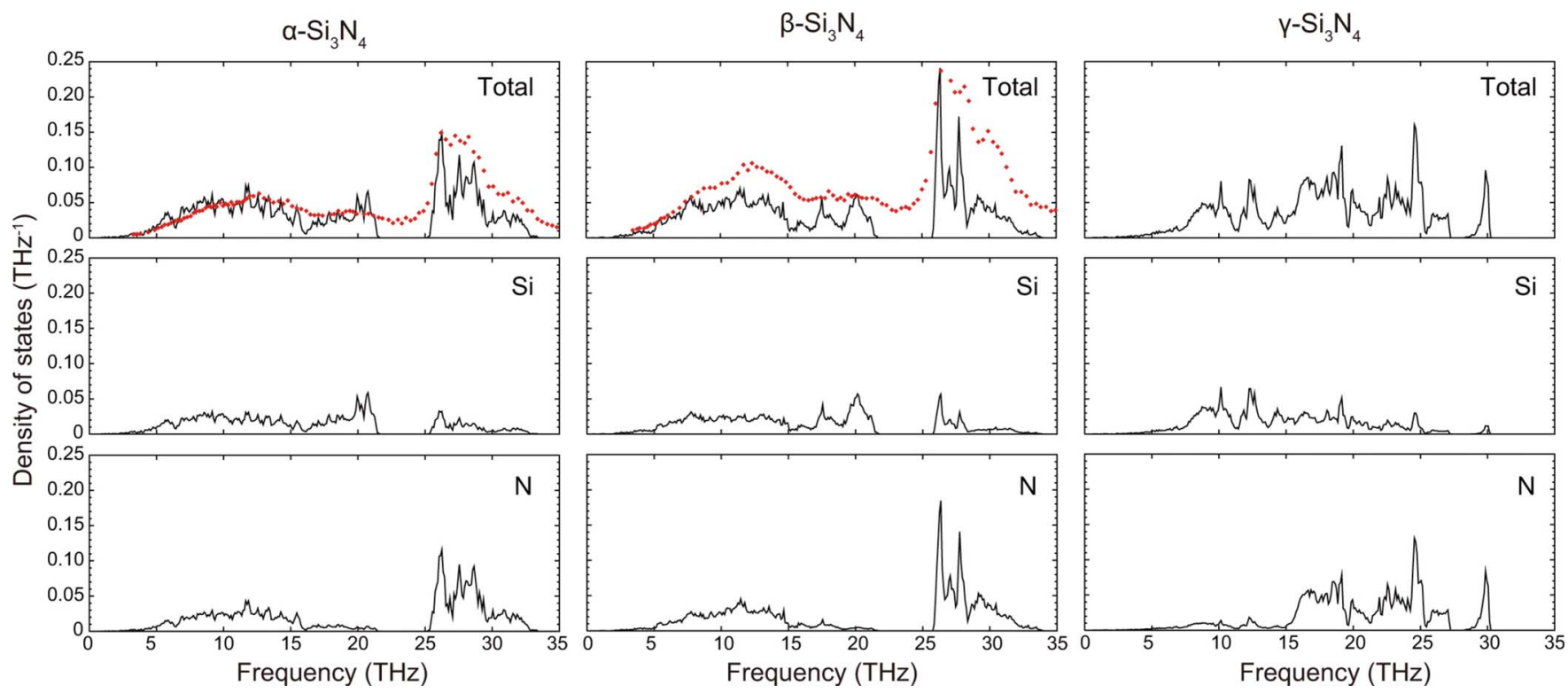

FIG. 3. (Color online) Total VDOS and projected partial VDOS in $\mathrm{Si}_{3} \mathrm{~N}_{4}$ polymorphs. With regard to the $\alpha$ and $\beta$ phase, experimental total VDOS data by Refs. 77 and 78 are shown by red dots. The experimental VDOS are rescaled as to make the highest peak in the data equal to the highest one of the calculated VDOS. Partial projected VDOS corresponds to the sum of all Si and N atoms, respectively.

$$
\int g_{\text {total }}(\omega) d \omega=1
$$

Partial VDOS for Si and $\mathrm{N}, g_{\mathrm{Si}}(\omega)$ and $g_{\mathrm{N}}(\omega)$, were obtained by summing up all local VDOS of corresponding atoms in the unit cell. Experimental total VDOS by neutron scattering technique ${ }^{77,78}$ is available for $\alpha$ and $\beta$ phases. The present $g_{\text {total }}(\omega)$ well reproduces them except that the calculated VDOS has phonon gap states between 22 and $25 \mathrm{THz}$. The presence of the gap might be ascribed to neglect of the $\mathrm{LO} / \mathrm{TO}$ splitting in the present calculations.

$g_{\text {total }}(\omega)$ of two hexagonal crystals, i.e., the $\alpha$ and $\beta$ phases, are similar. They can be divided into a few bands. The highest frequency band at above $25 \mathrm{THz}$ is ascribed to the vibration of $\mathrm{N}$ atoms for the bond stretching in $\mathrm{N}-\mathrm{Si}_{3}$ triangle or pyramid. The vibration of $\mathrm{Si}$ in $\mathrm{Si}-\mathrm{N}_{4}$ tetrahedra can be seen in the range of 15-20 THz. The vibration of $\mathrm{N}$ atoms for the bond bending of $\mathrm{N}-\mathrm{Si}_{3}$ triangle or pyramid is located in the range of $10-15 \mathrm{THz}$. The frequencies lower than $10 \mathrm{THz}$ is attributed to the vibrations of acoustic and optic branches distorting the whole $\mathrm{Si}-\mathrm{N}$ bonding network.

Figures 4 and 5 show orientation dependence of VDOS in $\beta$ - and $\alpha-\mathrm{Si}_{3} \mathrm{~N}_{4}$, respectively. Concerning $\mathrm{N}$ atoms with different Wyckoff notations in $\alpha$ - and $\beta$ - $\mathrm{Si}_{3} \mathrm{~N}_{4}, g_{N}(\omega)$ are separately shown. $\mathrm{N}$ sites in $a-\mathrm{Si}_{3} \mathrm{~N}_{4}$ are grouped into $2 a+2 b$ sites and two kinds of $6 c$ sites. In case of $\beta-\mathrm{Si}_{3} \mathrm{~N}_{4}$, the VDOS of $\mathrm{N}$ atoms at the $2 c$ and $6 h$ sites are indicated. The $x$ and $y$ axis are parallel to the basal plane and the $z$ axis corresponds to the [0001] direction. As clearly seen in these figures, $g_{\text {total }}(\omega)$ and $g_{\mathrm{Si}}(\omega)$ in both $\alpha$ - and $\beta$ - $\mathrm{Si}_{3} \mathrm{~N}_{4}$ are almost isotropic. This is the same for $g_{\mathrm{N}}(\omega)$ when the spectra of all $\mathrm{N}$ atoms in the unit cell are summed up. However, it does not mean that the local vibrations of individual atoms are totally isotropic. For example, partial VDOS for $\mathrm{N}$ sites at the $2 c$ and $6 h$ sites, $g_{\mathrm{N}(2 c)}(\omega)$ and $g_{\mathrm{N}(6 h)}(\omega)$, in $\beta$ - $\mathrm{Si}_{3} \mathrm{~N}_{4}$ are not iso- tropic. $\mathrm{N}(2 c)$ atoms in $\beta-\mathrm{Si}_{3} \mathrm{~N}_{4}$ have planar units of $\mathrm{N}-\mathrm{Si}_{3}$. The triangle is parallel to the basal plane. Vibration of the $\mathrm{N}$ atom in the direction parallel to the basal plane corresponds to the stretching mode of Si-N bond. The vibration perpendicular to the basal plane is the bending mode. As can be seen in Fig. $4, g_{\mathrm{N}(2 c)}(\omega)$ shows higher frequency for the stretching and lower frequency for the bending. $\mathrm{N}(6 h)$ atoms in $\beta-\mathrm{Si}_{3} \mathrm{~N}_{4}$ also exhibit planar N-Si $i_{3}$ units, which are perpendicular to the basal plane. Therefore the perpendicular component of $g_{\mathrm{N}(6 h)}(\omega)$ corresponds to the stretching mode of the Si-N bond, which shows higher frequency component as the case of the parallel component of $g_{\mathrm{N}(2 c)}(\omega)$. Similar anisotropy can be found in $\mathrm{N}$ atoms of $\alpha-\mathrm{Si}_{3} \mathrm{~N}_{4}$. These results can be explained by the fact that $\mathrm{Si}-\mathrm{N}$ bond is much stiffer against stretching than bending.

As shown in Fig. 6, the VDOS of $\gamma-\mathrm{Si}_{3} \mathrm{~N}_{4}$ differs from those of $\alpha$ - and $\beta-\mathrm{Si}_{3} \mathrm{~N}_{4}$. The frequencies lower than $15 \mathrm{THz}$ is attributed to the vibration of $\mathrm{Si}$ atom. The higher frequency part is mainly ascribed to the vibrations of $\mathrm{N}$ atom. $\mathrm{Si}$ atoms with octahedral and tetrahedral coordination show different frequencies. The tetrahedral $\mathrm{Si}$ atoms show larger frequencies, which can be ascribed to the fact that the $\mathrm{Si}($ tet)-N bond is stronger than the $\mathrm{Si}($ oct) $-\mathrm{N}$ bond.

\section{Thermodynamical properties at finite temperatures}

The temperature dependence of thermodynamical quantities such as Helmholtz free energy, vibrational entropy, and specific heat at constant volume can be calculated using VDOS. ${ }^{79}$ Using quasiharmonic approximation, ${ }^{79}$ thermal expansivity, and specific heat at constant pressure can be evaluated. Helmholtz free energy $(F)$ can be divided into two contributions, electronic and vibrational parts. In the case of an insulator like $\mathrm{Si}_{3} \mathrm{~N}_{4}$, electronic contribution to free energy at finite temperature can be neglected. $F$ as a function of 


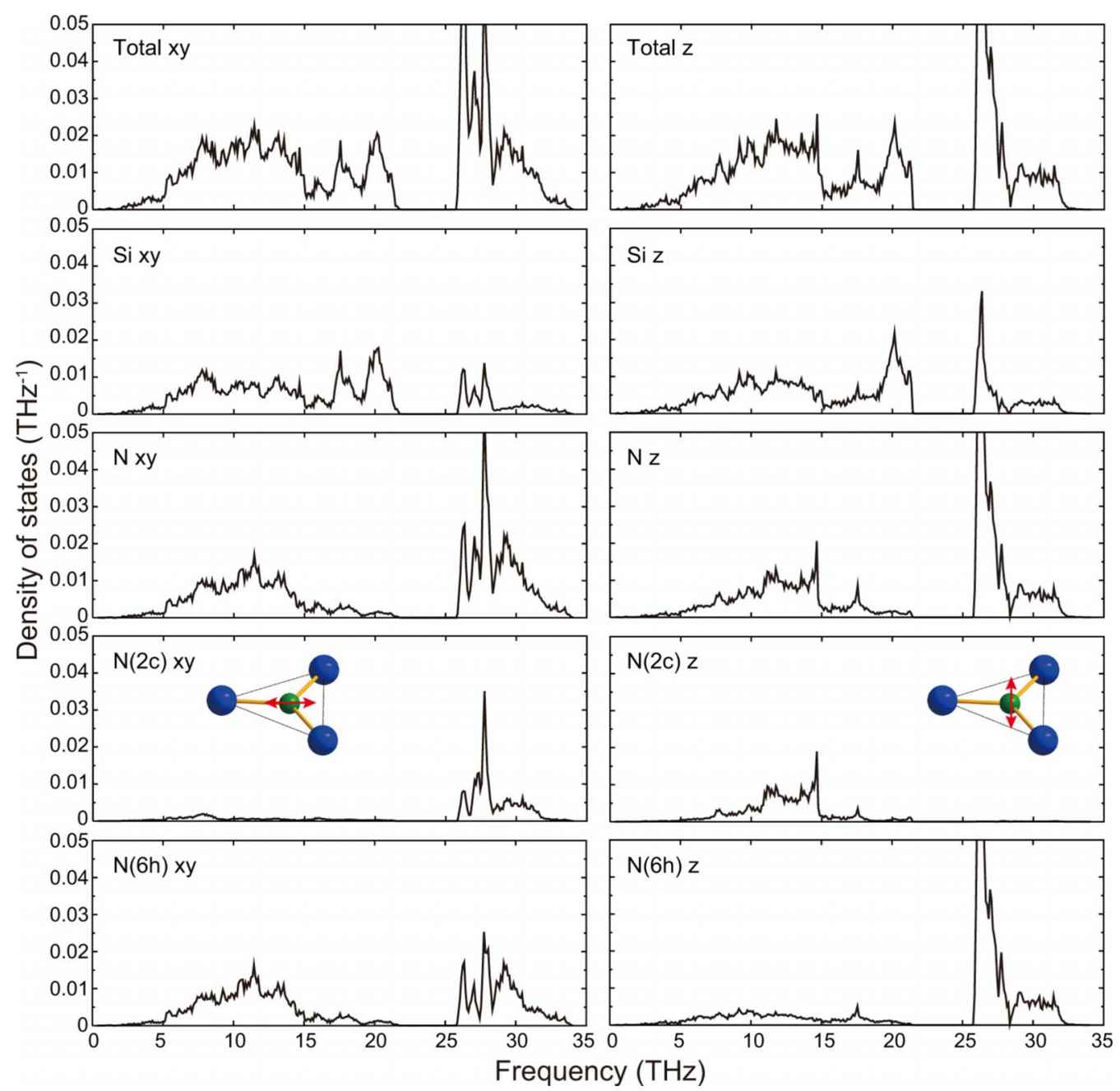

FIG. 4. (Color online) Projected total VDOS and partial VDOS of all Si, all $\mathrm{N}$ atoms, $\mathrm{N}$ atoms at the $2 c$ site, and $\mathrm{N}$ atoms at the $6 h$ site in $\beta-\mathrm{Si}_{3} \mathrm{~N}_{4}$. Left column corresponds to the average of VDOS in the $x$ and $y$ direction. Right column is for the VDOS in the $z$ direction.

volume $(V)$ and absolute temperature $(T)$ can be given by

$$
F(V, T)=E_{\mathrm{el}}(V)+F_{\mathrm{vib}}(V, T) .
$$

$E_{\mathrm{el}}(V)$ and $F_{\mathrm{vib}}(V, T)$ are total energy at $0 \mathrm{~K}$ calculated by DFT and vibrational Helmholtz free energy calculated from VDOS. $F_{\text {vib }}(V, T)$ is expressed as

$$
F_{\text {vib }}(V, T)=r k_{\mathrm{B}} T \int_{0}^{\infty} g_{\text {total }}(\omega, V) \cdot \ln \left(2 \sinh \frac{\hbar \omega}{2 k_{\mathrm{B}} T}\right) d \omega,
$$

where $r$ and $k_{B}$ are degree of freedom in a unit cell and the Boltzmann constant, respectively. The dependence of VDOS was obtained from phonon calculations with changing lattice volumes. Figure 7 shows the $F-V$ curves of $\mathrm{Si}_{3} \mathrm{~N}_{4}$ polymorphs at every $100 \mathrm{~K}$ from 0 to $1000 \mathrm{~K}$. Diamond symbols are actual data points obtained by the present calculations. The $F-V$ curves are obtained by least square fitting to the BurchMurnaghan second order equation of states. Broken lines connect the equilibrium volume at each temperature. Figure 8 shows the temperature dependence of the volume expansion coefficient, $\alpha$, of three polymorphs, which is defined by

$$
\alpha=\frac{1}{V} \frac{\partial V}{\partial T} .
$$

Although experimental data in literature are widely scattered, the present results are in reasonable agreement to them. Thermal expansion coefficients of the $\alpha$ and $\beta$ phases are different only by $<1 \times 10^{-7} \mathrm{~K}^{-1}$. On the other hand, the thermal expansion coefficients of the $\gamma$ phase is two times larger than those of the $\alpha$ and $\beta$ phases. In the lowtemperature region of $<100 \mathrm{~K}$, the volume expansion coefficients are negative in both $\alpha$ - and $\beta-\mathrm{Si}_{3} \mathrm{~N}_{4}$. For example, they are $-1.9 \times 10^{-7} \mathrm{~K}^{-1}$ and $-2.0 \times 10^{-7} \mathrm{~K}^{-1}$ at $90 \mathrm{~K}$ for $\alpha$ and $\beta$ - $\mathrm{Si}_{3} \mathrm{~N}_{4}$, respectively. Paszkowicz et al. ${ }^{59}$ have pointed out the possibility of negative expansion in $\gamma-\mathrm{Si}_{3} \mathrm{~N}_{4}$ from their $x$-ray diffraction at low temperature using synchrotronradiation source. However, they have reported that the negative expansion of $\gamma-\mathrm{Si}_{3} \mathrm{~N}_{4}$ is not found from their theoretical calculation. Similarly, our calculation does not show the negative expansion of $\gamma-\mathrm{Si}_{3} \mathrm{~N}_{4}$.

The bulk moduli $(B)$ of three phases were computed as a function of temperature. At $300 \mathrm{~K}$ they are 233, 245, and 310 GPa for $\alpha, \beta$, and $\gamma$ phase, respectively. Experimental $B$ of 


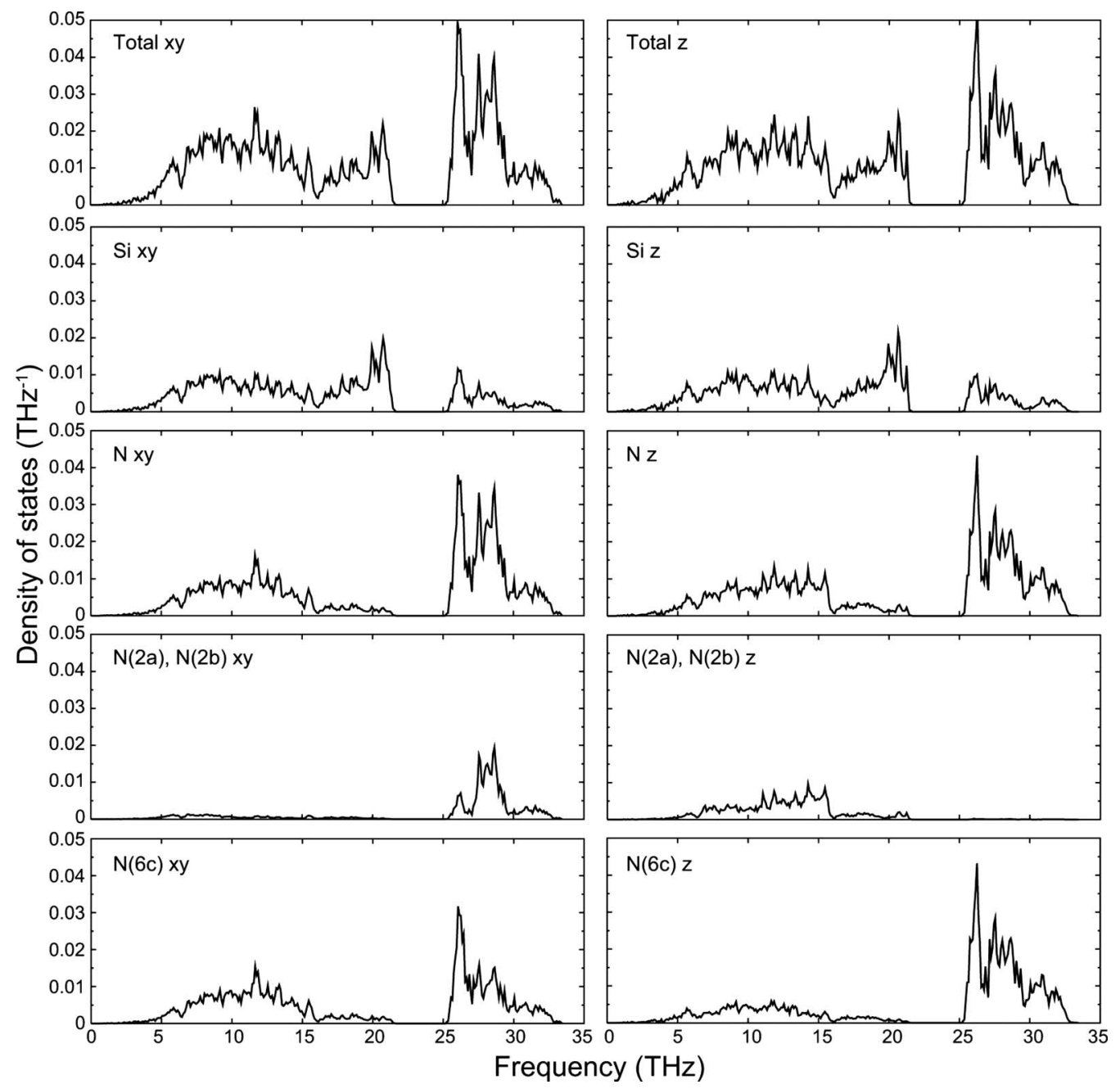

FIG. 5. Projected partial VDOS of all Si, all $\mathrm{N}$ atoms, $\mathrm{N}$ atoms at the $2 a$ and $2 b$ site, and $\mathrm{N}$ atoms at two types of the $6 c$ sites in $\alpha$-Si $\mathrm{N}_{3}$. Left column corresponds to the average of VDOS in the $x$ and $y$ direction. Right column is for the VDOS in the $z$ direction.

the $\alpha$ and $\beta$ phases in literature are widely scattered. It ranges from 228.5 to $291.7 \mathrm{GPa}$ for $\alpha-\mathrm{Si}_{3} \mathrm{~N}_{4} \cdot{ }^{45,47,49}$ For $\beta$-Si $\mathrm{N}_{4}$, the range from 211 to $270 \mathrm{GPa}$ has been reported. ${ }^{45-48,50-52,54}$ Therefore it is difficult to evaluate the magnitude of errors between theory and experiments. On the other hand, the present calculation shows good agreement with the experimental data for $\gamma-\mathrm{Si}_{3} \mathrm{~N}_{4} \cdot{ }^{43,56,57}$ Figure 9 shows the temperature dependence of $B$. It decreases with temperature in all three phases. The temperature dependence of $B$ has been reported only for $\beta$ phase. The dependence agrees satisfactory with some of the experimental report in the temperature range between 300 and $1200 \mathrm{~K}$.

Figure 10 shows the temperature dependence of specific heat and the difference of specific heat between the polymorphs of $\mathrm{Si}_{3} \mathrm{~N}_{4}$. One can directly obtain specific heat at constant volume $\left(C_{V}\right)$ from VDOS based on the harmonic approximation because the lattice volume is fixed in the method. On the other hand, experimental results are available for specific heat at constant pressure $\left(C_{P}\right)$. This can be calculated using a thermodynamical equation, $C_{P}-C_{V}$ $=\alpha^{2} V B T$. The temperature dependence of $C_{P}$ was reported by a few groups ${ }^{39,41,44}$ on both the $\alpha$ and $\beta$ phases, which are shown in Fig. 10. Unfortunately they are widely scattered

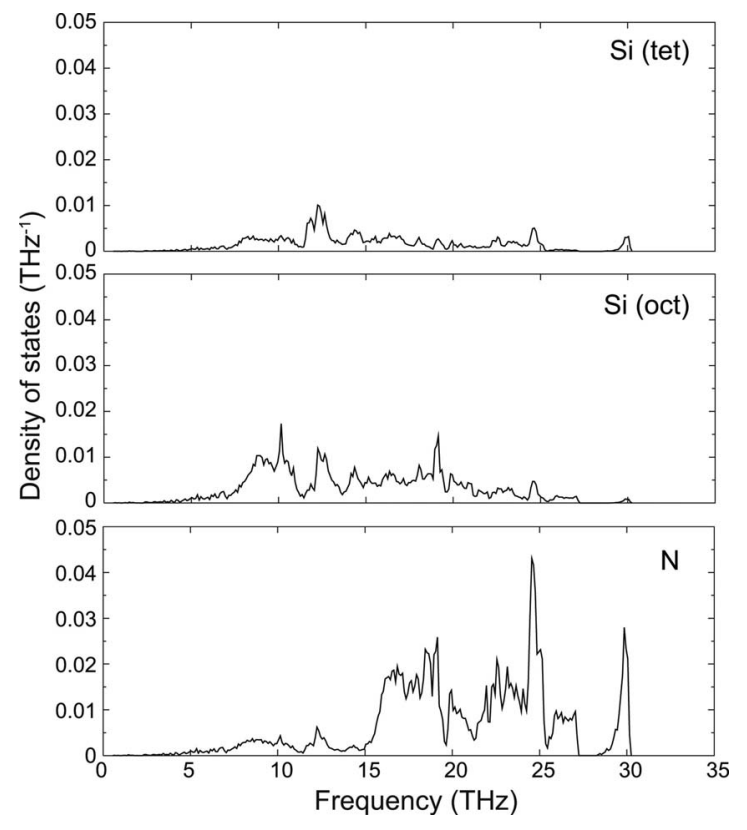

FIG. 6. VDOS, which is projected to the $x$ direction, of Si atoms with tetrahedral or octahedral coordination and $\mathrm{N}$ atom in $\gamma-\mathrm{Si}_{3} \mathrm{~N}_{4}$. 

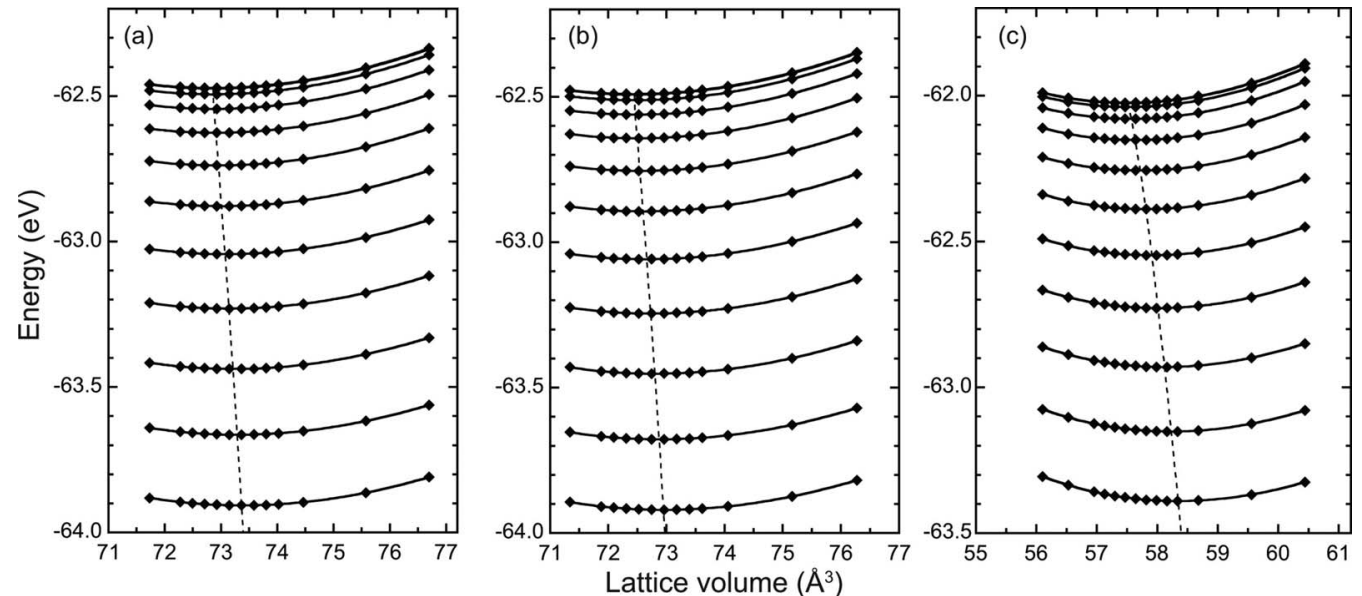

FIG. 7. Plots of calculated Helmholtz free energy to lattice volume per formula unit in (a) $\alpha-\mathrm{Si}_{3} \mathrm{~N}_{4}$, (b) $\beta-\mathrm{Si}_{3} \mathrm{~N}_{4}$, and (c) $\gamma$ - $\mathrm{Si}_{3} \mathrm{~N}_{4}$ from 0 to $1000 \mathrm{~K}$ in every $100 \mathrm{~K}$. Symbols represent actual data points in the present calculations. Bold lines are fitting curves using second order Birch-Murnaghan's equation of states. Broken lines connect the volume with the minimum energy at each temperature.

again and cannot be used to examine the validity of the theoretical results. Moreover, no $C_{P}$ of the $\gamma$ phase has been reported experimentally.

The difference of $C_{P}\left(\Delta C_{P}\right)$ is calculated by subtracting $C_{P}(\beta)$ from $C_{P}(\alpha)$ or $C_{P}(\gamma)$. As is the case with the thermal volume expansion, the difference of $C_{P}$ of $\alpha$ - and $\beta-\mathrm{Si}_{3} \mathrm{~N}_{4}$, $\Delta C_{P}(\alpha-\beta)$, is small as $<1 \mathrm{~J} \mathrm{~mol}^{-1} \mathrm{~K}^{-1}$ at all temperatures. However, detailed examination can find small differences in the temperature dependence of $C_{P}$, which can be related to the difference in the shape of VDOS.

Under the harmonic approximation, specific heat is expressed by integrating a product of $g(\omega)$ and a weighting function $W$ as shown below,

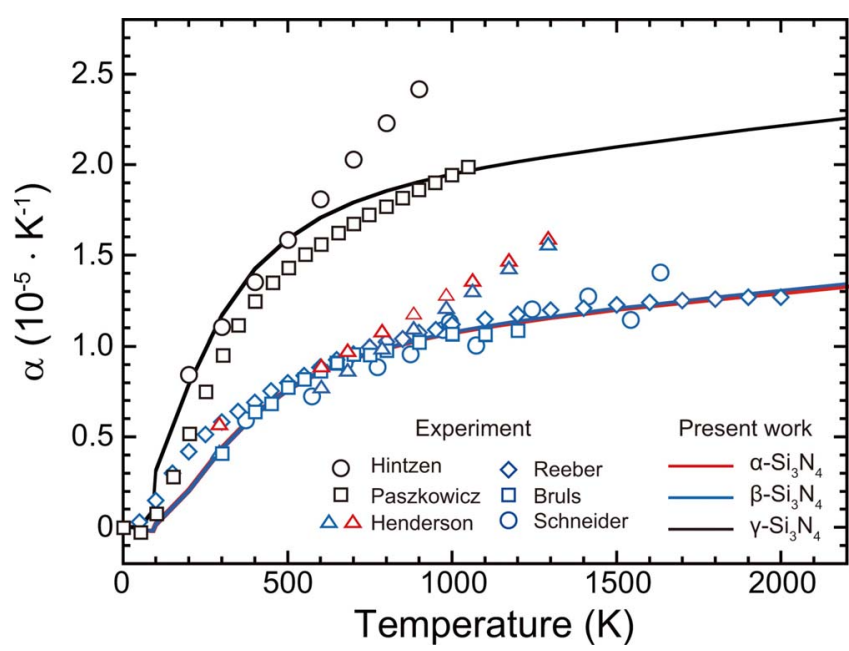

FIG. 8. (Color online) Plots of the calculated thermal volume expansivity of $\alpha-, \beta$-, and $\gamma-\mathrm{Si}_{3} \mathrm{~N}_{4}$ against temperatures. Solid line shows the present results. Red, blue, and black correspond to the results of the $\alpha, \beta$, and $\gamma$ phases, respectively. Symbols represent experimental data in the literatures (Refs. 44, 47, 58, 59, 80, and 81) Color setting for the symbols is the same as that of the lines.

$$
\begin{aligned}
C_{V}=r k_{\mathrm{B}} \int_{0}^{\infty} g(\omega) \cdot\left(\frac{\hbar \omega}{k_{\mathrm{B}} T}\right)^{2} \frac{\exp \left(\frac{\hbar \omega}{k_{\mathrm{B}} T}\right)}{\left[\exp \left(\frac{\hbar \omega}{k_{\mathrm{B}} T}\right)-1\right]^{2}} d \omega \\
=r k_{\mathrm{B}} \int_{0}^{\infty} g(\omega) \cdot W\left(\hbar \omega / k_{\mathrm{B}} T\right) d \omega \\
\left(W(x)=x^{2} \frac{\exp (x)}{[\exp (x)-1]^{2}}\right) .
\end{aligned}
$$

This equation implies that all phonon do not contribute to the specific heat at low temperatures. Figure 11 shows

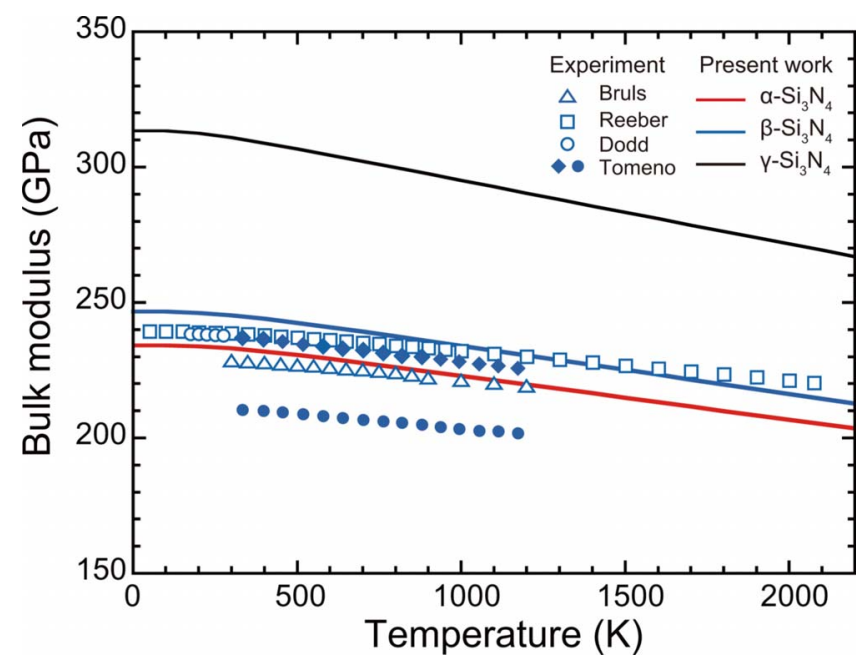

FIG. 9. (Color online) Dependence of the bulk modulus of $\alpha$-, $\beta$-, and $\gamma-\mathrm{Si}_{3} \mathrm{~N}_{4}$ on temperature. Solid line shows the present results. Red, blue, and black correspond to the results of $\alpha, \beta$, and $\gamma$ phases, respectively. Symbols represent experimental data in the literatures (Refs. 44, 46, 52, and 81) Color setting for the symbols is the same as that for the lines. Bulk moduli $(B)$ from Ref. 46 are calculated from reported Young's modulus $(E)$ and Poisson ratio $(\nu)$ using the equation, $B=E / 3(1-\nu)$. The highest and lowest data of $B$ from Ref. 46 are shown. 


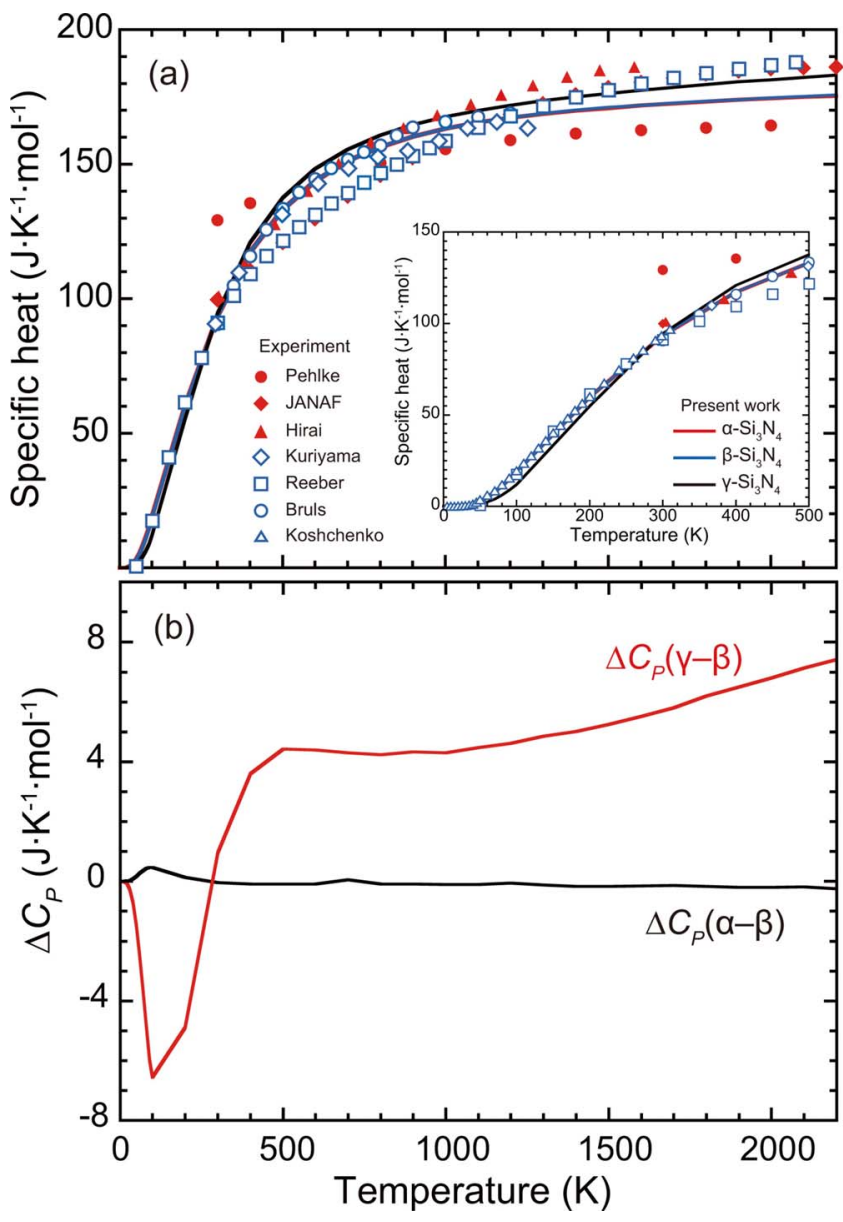

FIG. 10. (Color online) Plots of (a) the calculated specific heat and (b) the difference of specific heat against temperatures. In the panel of (a), solid line shows the present results. Red, blue, and black correspond to the results of $\alpha, \beta$, and $\gamma$ phases, respectively. Symbols represent experimental data in the literatures (Refs. 38-42, 44, and 81) Color setting of the symbols is the same as that of the lines. Inset in the panel of (a) shows low-temperature region from 0 to $500 \mathrm{~K}$. The data in Ref. 39 are plotted only in the inset.

$g(\omega) \cdot W\left(\hbar \omega / k_{B} T\right)$ as a function of phonon frequency, $\omega$, at four different temperatures. At temperatures lower than 200 $\mathrm{K}, C_{P}(\alpha)$ is larger than $C_{P}(\beta) . \Delta C_{P}(\alpha-\beta)$ reaches a positive maximum at $100 \mathrm{~K}$. As shown in Fig. 2, acoustic branches of $\alpha-\mathrm{Si}_{3} \mathrm{~N}_{4}$ in the direction of $\Gamma$-A have lower frequencies than those of $\beta-\mathrm{Si}_{3} \mathrm{~N}_{4}$. Moreover, there are clear localized optical modes at around $5 \mathrm{THz}$ in $\alpha-\mathrm{Si}_{3} \mathrm{~N}_{4}$ making a small hump in the VDOS. As can be seen in Fig. 9, the $\alpha$ phase has larger $g(\omega) W\left(\hbar \omega / k_{B} T\right)$ than the $\beta$ phase at low temperatures at around $100 \mathrm{~K}$. This is the reason why $\alpha-\mathrm{Si}_{3} \mathrm{~N}_{4}$ shows larger $C_{P}$ than $\beta-\mathrm{Si}_{3} \mathrm{~N}_{4}$ at the low temperatures.

The difference between $\gamma$ and $\beta, \Delta C_{P}(\gamma-\beta)$, is much larger than $\Delta C_{P}(\alpha-\beta)$. At the low-temperature region, $\Delta C_{P}(\gamma-\beta)$ is negative because VDOS distributes to higher frequency in the $\gamma$ phase, which can be seen by comparing plots of Fig. 11 at $100 \mathrm{~K}$. At higher temperatures above 300 $\mathrm{K}$, on the other hand, $\Delta C_{P}(\gamma-\beta)$ becomes positive. This can be explained by the fact that VDOS of $\alpha$ - and $\beta-\mathrm{Si}_{3} \mathrm{~N}_{4}$ are separately distributed into two regions, i.e., the lower $(<20 \mathrm{THz})$ and the higher $(>25 \mathrm{THz})$ frequencies. As dis-

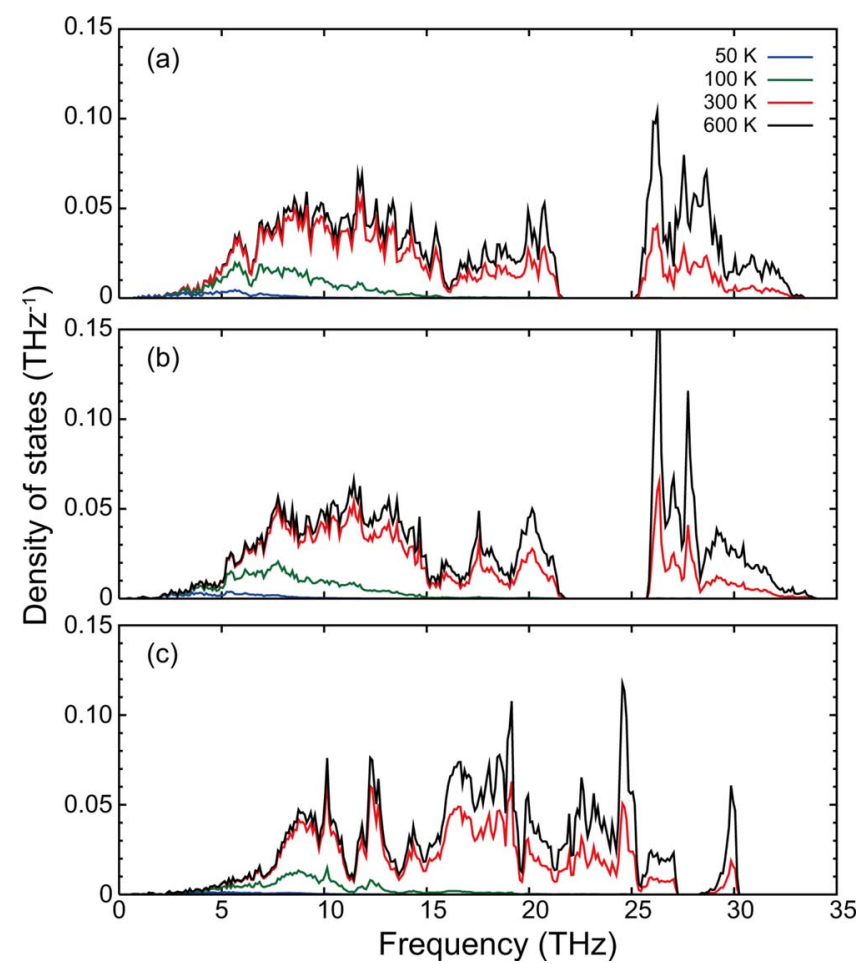

FIG. 11. (Color online) The function of $g(\omega) W\left(\hbar \omega / k_{B} T\right)$ against frequency at temperatures of 50,100, 300, and $600 \mathrm{~K}$ in (a) $\alpha$, (b) $\beta$, and (c) $\gamma$ phases.

cussed before, the separation can be ascribed to the presence of the strong $\mathrm{Si}-\mathrm{N}$ bonds in the planer $\mathrm{N}-\mathrm{Si}_{3}$ unit in both $\alpha$ and $\beta-\mathrm{Si}_{3} \mathrm{~N}_{4}$. Such a separation is not seen in $\gamma-\mathrm{Si}_{3} \mathrm{~N}_{4}$ which does not have the planer unit. Similar temperature dependence of the relative specific heat can be found in the cases of carbon allotrope, graphite and diamond, and cubic and hexagonal boron nitride $\left(c\right.$ - and $h$-BN) ${ }^{82}$ Graphite and $h$-BN have planar structures. On the other hand, diamond and $c$-BN is a three-dimensional construction. They show lower specific heat than the planar ones, graphite and $h-\mathrm{BN}$, at low temperatures. At higher temperatures, the specific heat of the planar ones becomes smaller.

\section{Relative phase stability at finite temperatures}

Relative phase stability between $\alpha$ - and $\beta$ - $\mathrm{Si}_{3} \mathrm{~N}_{4}$ has been unknown for a long time. First-principles calculations have suggested that $\beta-\mathrm{Si}_{3} \mathrm{~N}_{4}$ is the ground-state structure. ${ }^{6}$ However, relative phase stability at finite temperatures is not yet clarified by theoretical calculations. Recently, energetics of $\mathrm{Si}_{3} \mathrm{~N}_{4}$ polymorphs were experimentally examined by hightemperature oxide-melt-drop solution calorimetry. Ling et $a l .{ }^{83}$ concluded that the difference in the formation enthalpies of $\alpha$ - and $\beta-\mathrm{Si}_{3} \mathrm{~N}_{4}$ is small and that relative stability in these two phases is indistinguishable within their experimental accuracy of $\pm 22 \mathrm{~kJ} / \mathrm{mol}\left( \pm 0.23 \mathrm{eV} / \mathrm{Si}_{3} \mathrm{~N}_{4}\right)$. Zhang et al. ${ }^{84}$ reported that the enthalpy of transformation from $\beta$ - to $\gamma-\mathrm{Si}_{3} \mathrm{~N}_{4}$ is $80.2 \pm 9.6 \mathrm{~kJ} / \mathrm{mol}$.

The phase stability of condensed matter under an ambient condition can be judged from comparison of Helmholtz free energies $(F)$ because $P V$ term is generally negligible under 


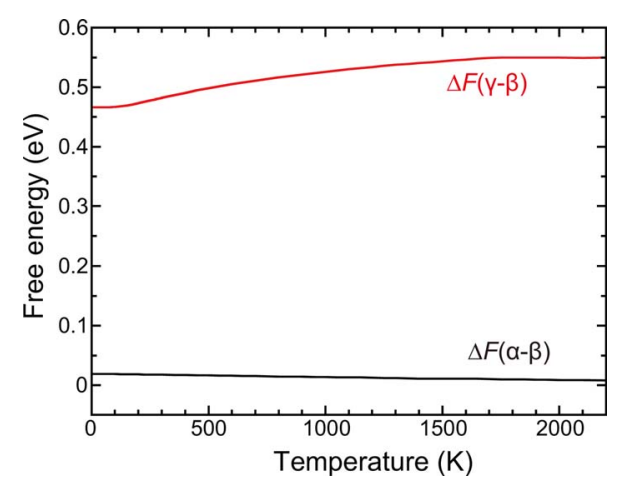

FIG. 12. (Color online) The dependence of Helmholtz free energy difference $(\Delta F)$ on temperature.

the standard pressure of $0.1 \mathrm{MPa}$. Figure 12 shows the difference of Helmholtz free energies $(\Delta F)$ per formula unit between polymorphs. $\Delta F$ is calculated by subtraction of $F$ of the $\beta$ phase from those of the $\alpha$ and $\gamma$ phases. Therefore, positive $\Delta F$ means that the $\beta$ phase is more stable to the other phase. $\Delta F$ between $\alpha$ and $\beta, \Delta F_{\alpha-\beta}$, is $18 \mathrm{meV}$ at $0 \mathrm{~K}$. The energy difference between the $\alpha$ and $\beta$ phases is slightly changed by including zero-point vibration energy. With the increase in temperature, the magnitude of $\Delta F_{\alpha-\beta}$ becomes smaller but keeps positive in the whole range of temperatures. The value of $\Delta F_{\alpha-\beta}$ is $9 \mathrm{meV}$ at $2000 \mathrm{~K}$. Our $\Delta F_{\alpha-\beta}$ is larger than the results by the empirical force field simulation, ${ }^{16}$ in which $\Delta F_{\alpha-\beta}$ was reported to be only $0.8 \mathrm{meV} / \mathrm{Si}_{3} \mathrm{~N}_{4}$ at $300 \mathrm{~K}$ and $5 \mathrm{meV} / \mathrm{Si}_{3} \mathrm{~N}_{4}$ at $2000 \mathrm{~K}$. It should be noted that their temperature dependence of $\Delta F_{\alpha-\beta}$ is opposite to our result. The major source of the discrepancy may be the fact that their simulation did not include the thermal expansion. On the basis of the present calculations, we can conclude that $\beta-\mathrm{Si}_{3} \mathrm{~N}_{4}$ is more stable than $\alpha-\mathrm{Si}_{3} \mathrm{~N}_{4}$ in the temperature range from 0 to $2000 \mathrm{~K}$. In other words, $\alpha-\mathrm{Si}_{3} \mathrm{~N}_{4}$ is not the low-temperature phase but a metastable phase under the ordinary pressure. The free energy difference between two phases is smaller than $18 \mathrm{meV}$ or $1.7 \mathrm{~kJ} / \mathrm{mol}$. This is the reason why the energy difference has not been measured directly by the calorimetric methods. ${ }^{83} \alpha-\mathrm{Si}_{3} \mathrm{~N}_{4}$ could be formed by kinetic reasons. The Helmholtz free energy of the $\gamma$ phase relative to the $\beta$ phase, $\Delta F_{\gamma-\beta}$, is $0.48 \mathrm{eV}$ and $0.55 \mathrm{eV}$ at $300 \mathrm{~K}$ and $2000 \mathrm{~K}$, respectively. The magnitude of $\Delta F_{\gamma-\beta}$ becomes larger with the increase in temperature. Calculated $\Delta F_{\gamma-\beta}$ can be directly compared to the enthalpy of transformation from $\beta$ - to $\gamma-\mathrm{Si}_{3} \mathrm{~N}_{4}$ because the value of $P \Delta V$ term is $9.4 \times 10^{-6} \mathrm{eV}$ at $300 \mathrm{~K}$ under the pressure of $1 \mathrm{~atm}$ and is quite negligible. In comparison to the reported value, $0.831 \pm 0.010 \mathrm{eV},{ }^{84}$ our calculation underestimate the difference in the formation enthalpy between $\gamma$ - and $\beta-\mathrm{Si}_{3} \mathrm{~N}_{4}$.

The effect of thermal expansion on Helmholtz free energy is evaluated by a calculation of $\Delta F$ with a fixed lattice volume at $0 \mathrm{~K}, \Delta F\left(V_{0 \mathrm{~K}}\right) . \Delta F\left(V_{0 \mathrm{~K}}\right)_{\alpha-\beta}$ and $\Delta F\left(V_{0 \mathrm{~K}}\right)_{\gamma-\beta}$ are 9 $\mathrm{meV}$ and $0.61 \mathrm{eV}$ at $2000 \mathrm{~K}$, respectively. $\Delta F$ between the $\alpha$ and $\beta$ phases are same in the calculations with and without the effect of thermal expansion. This is because the thermal expansivity is almost similar between the $\alpha$ and $\beta$ phases as is shown in Fig. 8. On the other hand, $\Delta F\left(V_{0 \mathrm{~K}}\right)_{\gamma-\beta}$ is $10 \%$

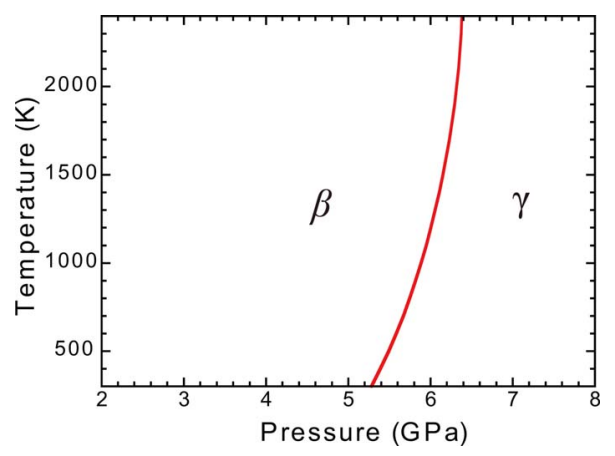

FIG. 13. (Color online) Relationship between the transition pressure from $\beta$ to $\gamma$ phases and temperature.

larger than $\Delta F_{\gamma-\beta}$ including the effect of thermal expansion. The thermal expansion coefficient of the $\gamma$ phase is clearly different from that of the $\beta$ phase. In such case, the effect of thermal expansion should be included for quantifying thermodynamical parameters with high accuracy.

Theoretical transformation pressure can be determined from a common tangent of $F-V$ curves of the $\beta$ and $\gamma$ phases. Figure 13 shows the relationship between the $\beta \rightarrow \gamma$ transition pressure $\left(P_{\beta \rightarrow \gamma}\right)$ and temperature. By the present calculations, $P_{\beta \rightarrow \gamma}$ is $5.3 \mathrm{GPa}$ and $6.3 \mathrm{GPa}$ at $300 \mathrm{~K}$ and $2000 \mathrm{~K}$, respectively. Kroll ${ }^{85}$ reported that $P_{\beta \rightarrow \gamma}$ of $12 \mathrm{GPa}$ from first-principles calculations at $0 \mathrm{~K}$. The discrepancy between the present study and his work may be originated from the use of different exchange correlation potentials, i.e., LDA in the present study and GGA in his work. The experimental $P_{\beta \rightarrow \gamma}$ is scattered from 10 to $36 \mathrm{GPa}$ depending upon synthesis conditions, high-pressure apparatus, and starting powders as summarized by Zhang et al. ${ }^{83}$ The present calculation seemingly underestimates $P_{\beta \rightarrow \gamma}$ in comparison to the experimental data. More works may be required to evaluate the equilibrium transition pressure with higher reliability.

$P_{\beta \rightarrow \gamma}$ increases with the rise of temperature in Fig. 13. According to the Clausius-Clapeyron relationship, gradient of the phase boundary is given by $d T / d P=\Delta S / \Delta V$, where $\Delta S$ and $\Delta V$ are changes in entropy and volume, respectively. The phase transformation from $\beta$ to $\gamma$ is accompanied by the shrinkage of the lattice volume. The present phonon calculation shows that vibrational entropy of the $\gamma$ phase is smaller than that of the $\beta$ phase at the temperature range of our interest. Both of $\Delta V$ and $\Delta S$ are negative. Thereby $P_{\beta \rightarrow \gamma}$ shows positive temperature dependence. It has been reported that high-pressure processing is essential to synthesize $\gamma-\mathrm{Si}_{3} \mathrm{~N}_{4}{ }^{86-88}$ According to the present study, this is most probably by the kinetic reasons.

\section{SUMMARY}

Lattice dynamics and thermodynamical properties of $\alpha$-, $\beta-$, and $\gamma-\mathrm{Si}_{3} \mathrm{~N}_{4}$ are evaluated by first-principles calculation using PAW method. Results can be summarized as follows:

(1) All phonon branches in the Brillouin zone have real frequencies in three phases, which means that these polymorphs of $\mathrm{Si}_{3} \mathrm{~N}_{4}$ are dynamically stable.

(2) Two hexagonal crystals, i.e., $\alpha$ - and $\beta$ - $\mathrm{Si}_{3} \mathrm{~N}_{4}$, exhibit VDOS of close resemblance. The presence of the planer 
$\mathrm{N}-\mathrm{Si}_{3}$ units in these crystals contributes to the anisotropic local VDOS of $\mathrm{N}$ atoms. The bond stretching in the $\mathrm{N}-\mathrm{Si}_{3}$ units makes the high-frequency VDOS band at above 25 THz. On the other hand, the bond-bending modes are located in the range of 10-15 $\mathrm{THz}$.

(3) Such an anisotropic behavior is not found in $\gamma-\mathrm{Si}_{3} \mathrm{~N}_{4}$ showing cubic spinel structure with no $\mathrm{N}-\mathrm{Si}_{3}$ units. Their tetrahedral $\mathrm{Si}$ atoms show larger frequencies than the octahedral ones, which can be ascribed to the fact that the $\mathrm{Si}$ (tet)-N bond is stronger than the $\mathrm{Si}($ oct)-N bond.

(4) Using the quasiharmonic approximation, volume expansivity, $\alpha$, bulk modulus, $B$, and specific heats $C_{P}$ and $C_{V}$ for three crystals are calculated as a function of temperature. Although experimental data have been widely scattered, the theoretical results are consistent to experimental data.

(5) The difference of the temperature dependence of $C_{P}$ among three phases can be related to the difference in the shape of VDOS. As compared to the $\alpha$ and $\beta$ phases, the $\gamma$ phase shows lower $C_{P}$ at low temperatures and higher $C_{P}$ at high temperatures. This can be explained by the presence of the planer $\mathrm{N}-\mathrm{Si}_{3}$ units only in the hexagonal polymorphs forming high-frequency phonon band at above $25 \mathrm{THz}$.

(6) By comparison of Helmholtz free energies, $F, \beta-\mathrm{Si}_{3} \mathrm{~N}_{4}$ is concluded to be more stable than $\alpha-\mathrm{Si}_{3} \mathrm{~N}_{4}$ in the temperature range from 0 to $2000 \mathrm{~K}$. In other words, $\alpha-\mathrm{Si}_{3} \mathrm{~N}_{4}$ is not the low-temperature phase but a metastable phase under the ordinary pressure. $\alpha-\mathrm{Si}_{3} \mathrm{~N}_{4}$ could be formed by kinetic reasons.

(7) Transition pressure from $\beta$ to $\gamma$ phase is calculated from the common tangent of $F-V$ curves of two phases at each temperature. The $T-P$ phase boundary shows positive gradient as the result of negative $\Delta S$ and $\Delta V$ in the ClausiusClapeyron relationship.

\section{ACKNOWLEDGMENTS}

This work was supported by three programs from the Ministry of Education, Culture, Sports, Science and Technology of Japan, i.e., the Grant-in-Aids for Scientific Research (A), Priority Area on "atomic scale modification," No. 474, and the global COE program.
${ }^{1}$ R. J. Sokel, J. Phys. Chem. Solids 41, 899 (1980).

${ }^{2}$ S.-Y. Ren and W. Y. Ching, Phys. Rev. B 23, 5454 (1981).

${ }^{3}$ J. Robertson, Philos. Mag. B 44, 215 (1981).

${ }^{4}$ Y.-N. Xu and W. Y. Ching, Physica B (Amsterdam) 150, 32 (1988).

${ }^{5}$ S.-D. Mo, L. Ouyang, W.-Y. Ching, I. Tanaka, Y. Koyama, and R. Riedel, Phys. Rev. Lett. 83, 5046 (1999).

${ }^{6}$ W.-Y. Ching, L. Ouyang, and J. D. Gale, Phys. Rev. B 61, 8696 (2000).

${ }^{7}$ R. Belkada, T. Shibayanagi, M. Naka, and M. Kohyama, J. Am. Ceram. Soc. 83, 2449 (2000).

${ }^{8}$ R. Belkada, M. Kohyama, T. Shibayanagi, and M. Naka, Phys. Rev. B 65, 092104 (2002).

${ }^{9}$ A. Y. Liu and M. L. Cohen, Phys. Rev. B 41, 10727 (1990).

${ }^{10}$ A. Reyes-Serrato, D. H. Galvan, and I. L. Garzon, Phys. Rev. B 52, 6293 (1995).

${ }^{11}$ S. Ogata, N. Hirosaki, C. Kocer, and H. Kitagawa, Phys. Rev. B 64, 172102 (2001).

${ }^{12}$ S. Ogata, N. Hirosaki, C. Kocer, and H. Kitagawa, J. Mater. Res. 18, 1168 (2003).

${ }^{13}$ C. Kocer, N. Hirosaki, and S. Ogata, Phys. Rev. B 67, 035210 (2003).

${ }^{14}$ J. Chen, L. Ouyang, P. Rulis, A. Misra, and W. Y. Ching, Phys. Rev. Lett. 95, 256103 (2005).

${ }^{15}$ Y. Cai, L. Zhang, Q. Zeng, L. Cheng, and Y. Xu, Phys. Rev. B 74, 174301 (2006).

${ }^{16}$ J. A. Wendel and W. A. Goddard III, J. Chem. Phys. 97, 5048 (1992).

${ }^{17}$ A. P. Mirgorodsky, M. I. Baraton, and P. Quintard, Phys. Rev. B 48, 13326 (1993).

${ }^{18}$ W.-Y. Ching, Y.-N. Xu, J. D. Gale, and M. Rühle, J. Am. Ceram. Soc. 81, 3189 (1998).

${ }^{19}$ J. Dong and O. F. Sankey, J. Appl. Phys. 87, 7380 (2000).

${ }^{20}$ C. M. Fang, G. A. de Wijs, H. T. Hintzen, and G. de With, J.
Appl. Phys. 93, 5175 (2003).

${ }^{21}$ I. Tanaka, S. Nasu, H. Adachi, Y. Miyamoto, and K. Niihara, Acta Metall. Mater. 40, 1995 (1992).

${ }^{22}$ I. Tanaka, K. Niihara, S. Nasu, and H. Adachi, J. Am. Ceram. Soc. 76, 2833 (1993).

${ }^{23}$ T. Nakayasu, T. Yamada, I. Tanaka, H. Adachi, and S. Goto, J. Am. Ceram. Soc. 80, 2525 (1997).

${ }^{24}$ T. Nakayasu, T. Yamada, I. Tanaka, H. Adachi, and S. Goto, J. Am. Ceram. Soc. 81, 565 (1998).

${ }^{25}$ C. M. Fang and R. Metselaar, J. Phys.: Condens. Matter 16, 2931 (2004).

${ }^{26}$ K. Tatsumi, I. Tanaka, H. Adachi, and M. Yoshiya, Phys. Rev. B 66, 165210 (2002).

${ }^{27}$ K. Tatsumi, T. Mizoguchi, S. Yoshioka, T. Yamamoto, T. Suga, T. Sekine, and I. Tanaka, Phys. Rev. B 71, 033202 (2005).

${ }^{28}$ P. Mori-Sánchez, M. Marqués, A. Beltrán, J. Z. Jiang, L. Gerward, and J. M. Recio, Phys. Rev. B 68, 064115 (2003).

${ }^{29}$ F. Alvarez and A. A. Valladares, Phys. Rev. B 68, 205203 (2003).

${ }^{30}$ J. C. Idrobo, H. Iddir, S. Öğüt, A. Ziegler, N. D. Browning, and R. O. Ritchie, Phys. Rev. B 72, 241301(R) (2005).

${ }^{31}$ P. Rulis, J. Chen, L. Ouyang, W. Y. Ching, X. Su, and S. H. Garofalini, Phys. Rev. B 71, 235317 (2005).

${ }^{32}$ S. Ogata, N. Hirosaki, C. Kocer, and Y. Shibutani, Acta Mater. 52, 233 (2004).

${ }^{33}$ N. Hirosaki, C. Kocer, S. Ogata, and K. Tatsumi, Phys. Rev. B 71, 104105 (2005).

${ }^{34}$ W. Y. Ching, J. Chen, P. Rulis, L. Ouyang, and A. Misra, J. Mater. Sci. 41, 5061 (2006).

${ }^{35}$ M. Yoshiya, H. Adachi, and I. Tanaka, J. Am. Ceram. Soc. 82, 3231 (1999).

${ }^{36}$ M. Yoshiya, I. Tanaka, and H. Adachi, Acta Mater. 48, 4641 (2000).

${ }^{37}$ R. Grün, Acta Crystallogr., Sect. B: Struct. Crystallogr. Cryst. 
Chem. 35, 800 (1979).

${ }^{38}$ R. D. Pehlke and J. F. Elliott, Trans. Metall. Soc. AIME 215, 781 (1959).

${ }^{39}$ V. I. Koshchenko and Ya. Kh. Grinberg, Inorg. Mater. 18, 903 (1982).

${ }^{40}$ T. Hirai, S. Hayashi, and K. Niihara, Am. Ceram. Soc. Bull. 57, 1126 (1978).

${ }^{41}$ M. Kuriyama, Y. Inomata, T. Kujima, and Y. Hasegawa, Am. Ceram. Soc. Bull. 57, 1119 (1978).

${ }^{42} \mathrm{M}$. W. Chase, Jr., NIST-JANAF Thermochemical Tables, 4th ed. (American Institute of Physics, New York, 1998).

${ }^{43}$ H. He, T. Sekine, T. Kobayashi, H. Hirosaki, and I. Suzuki, Phys. Rev. B 62, 11412 (2000).

${ }^{44}$ R. J. Bruls, H. T. Hintzen, G. de With, R. Metselaar, and J. C. van Miltenburg, J. Phys. Chem. Solids 62, 783 (2001).

${ }^{45}$ L. Cartz and J. D. Jorgensen, J. Appl. Phys. 52, 236 (1981).

${ }^{46}$ I. Tomeno, Jpn. J. Appl. Phys. 20, 1751 (1981).

${ }^{47}$ O. Yeheskel and Y. Gefen, Mater. Sci. Eng. 71, 95 (1985).

${ }^{48}$ E. S. Fisher, M. H. Manghnani, J-. F. Wang, and J. L. Routbort, J. Am. Ceram. Soc. 75, 908 (1992).

${ }^{49}$ M. B. Kruger, J. H. Nguyen, Y. M. Li, W. A. Caldwell, M. H. Manghnani, and R. Jeanloz, Phys. Rev. B 55, 3456 (1997).

${ }^{50}$ Y. M. Li, M. B. Kruger, J. H. Nguyen, W. A. Caldwell, and R. Jeanloz, Solid State Commun. 103, 107 (1997).

${ }^{51}$ R. Vogelgesang, M. Grimsditch, and J. S. Wallace, Appl. Phys. Lett. 76, 982 (2000).

${ }^{52}$ S. P. Dodd, M. Cankurtaran, G. A. Saunders, and B. James, J. Mater. Sci. 36, 2557 (2001).

${ }^{53}$ J. C. Hay, E. Y. Sun, G. M. Pharr, P. F. Becher, and K. B. Alexander, J. Am. Ceram. Soc. 81, 2661 (1998).

${ }^{54}$ R. J. Bruls, H. T. Hintzen, G. de With, and R. Metselaar, J. Eur. Ceram. Soc. 21, 263 (2001).

${ }^{55}$ P. Mori-Sánchez, R. Franco, A. Martín Pendás, V. Luaña, and J. M. Recio, Europhys. Lett. 54, 760 (2001).

${ }^{56}$ E. Soignard, M. Somayazulu, J. Dong, O. F. Sankey, and P. F. McMillan, J. Phys.: Condens. Matter 13, 557 (2001).

${ }^{57}$ J. Z. Jiang, H. Lindelov, L. Gerward, K. Ståhl, J. M. Recio, P. Mori-Sanchez, S. Carlson, M. Mezouar, E. Dooryhee, A. Fitch, and D. J. Frost, Phys. Rev. B 65, 161202 (2002).

${ }^{58}$ H. T. Hintzen, M. R. M. M. Hendrix, H. Wondergem, C. M. Fang, T. Sekine, and G. de With, J. Alloys Compd. 351, 40 (2003).

${ }^{59}$ W. Paszkowicz, R. Minikayev, P. Piszora, M. Knapp, C. Bähtz, J. M. Recio, M. Marqués, P. Mori-Sánchez, L. Gerward, and J. Z. Jiang, Phys. Rev. B 69, 052103 (2004).

${ }^{60}$ D. du Boulay, N. Ishizawa, T. Atake, V. Streltsov, K. Furuyad, and F. Munakata, Acta Crystallogr., Sect. B: Struct. Sci. 60, 388 (2004).

${ }^{61}$ W. Kohn and L. J. Sham, Phys. Rev. 140, A1133 (1965).

${ }^{62}$ G. Kresse and J. Furthmüller, Phys. Rev. B 54, 11169 (1996).

${ }^{63}$ G. Kresse and J. Furthmüller, Comput. Mater. Sci. 6, 15 (1996).

${ }^{64}$ P. E. Blöchl, Phys. Rev. B 50, 17953 (1994).

${ }^{65}$ D. M. Ceperley and B. J. Alder, Phys. Rev. Lett. 45, 566 (1980).

${ }^{66}$ H. J. Monkhorst and J. D. Pack, Phys. Rev. B 13, 5188 (1976).

${ }^{67}$ J. P. Poirier, Introduction to the Physics of the Earth's Interior (Cambridge University Press, New York, 2000).

${ }^{68}$ G. Kresse, J. Furthmüller, and J. Hafner, Europhys. Lett. 32, 729 (1995).

${ }^{69}$ K. Parlinski, Z. Q. Li, and Y. Kawazoe, Phys. Rev. Lett. 78, 4063 (1997).

${ }^{70}$ K. Kunc and R. M. Martin, Phys. Rev. Lett. 48, 406 (1982).

${ }^{71}$ X. Gonze and C. Lee, Phys. Rev. B 55, 10355 (1997).

${ }^{72}$ S. Baroni, S. de Gironcoli, A. D. Corso, and P. Giannozzi, Rev. Mod. Phys. 73, 515 (2001).

${ }^{73}$ H. Toraya, J. Appl. Crystallogr. 33, 95 (2000).

${ }^{74}$ M. Yashima, Y. Ando, and Y. Tabira, J. Phys. Chem. B 111, 3609 (2007).

${ }^{75}$ C. Sevik and C. Bulutay, J. Mater. Sci. 42, 6555 (2007).

${ }^{76}$ R. F. Zhang, S. H. Sheng, and S. Veprek, Appl. Phys. Lett. 90, 191903 (2007)

${ }^{77}$ C.-K. Loong, P. Vashishta, R. K. Kalia, and I. Ebbsjö, Europhys. Lett. 31, 201 (1995).

${ }^{78}$ C.-K. Loong, J. Eur. Ceram. Soc. 19, 2241 (1999).

${ }^{79}$ M. T. Dove, Structure and Dynamics (Oxford University Press, New York, 2003).

${ }^{80}$ C. M. B. Henderson and D. Taylor, Trans. J. Br. Ceram. Soc. 74, 49 (1975).

${ }^{81}$ R. R. Reeber, Therm. Conduct. 27, 525 (2005).

${ }^{82}$ T. Tohei, A. Kuwabara, F. Oba, and I. Tanaka, Phys. Rev. B 73, 064304 (2006).

${ }^{83}$ Y. Zhang, A. Navrotsky, and T. Sekine, J. Mater. Res. 21, 41 (2006).

${ }^{84}$ J.-J. Liang, L. Topor, A. Navrotsky, and M. Mitomo, J. Mater. Res. 14, 1959 (1999).

${ }^{85}$ P. Kroll, J. Solid State Chem. 176, 530 (2003).

${ }^{86}$ A. Zerr, G. Miehe, G. Serghiou, M. Schwarz, E. Kroke, R. Riedel, H. Fueß, P. Kroll, and R. Boehler, Nature (London) 400, 340 (1999).

${ }^{87}$ M. Schwarz, G. Miehe, A. Zerr, E. Kroke, B. T. Poe, H. Fuess, and R. Riedel, Adv. Mater. (Weinheim, Ger.) 12, 883 (2000).

${ }^{88}$ T. Sekine, H. He, T. Kobayashi, M. Zhang, and F. Xu, Appl. Phys. Lett. 76, 3706 (2000). 